\title{
Bacteroides forsythus: sensibilidade a antimicrobianos em amostras de pacientes portadores de periodontite
}

\section{Bacteroides forsythus: sensitivity to antimicrobial agents in samples from patients with periodontitis}

\author{
Roberto Fraga Moreira LOTUFO* \\ Claudio Mendes PANNUTI** \\ Maria da Conceição SARAIVA***
}

\begin{abstract}
LOTUFO, R. F. M.; PANNUTI, C. M.; SARAIVA, M. da C. Bacteroides forsythus: sensibilidade a antimicrobianos em amostras de pacientes portadores de periodontite. Pesqui Odontol Bras, v. 15, n. 1, p. 47-50, jan./mar. 2001.

Os autores realizaram teste de sensibilidade antimicrobiana in vitro (técnica de diluição em ágar) para 105 cepas de $B$. forsythus obtidas de pacientes portadores de periodontite. De acordo com o teste realizado, o microrganismo demonstrou ser sensivel ao metronidazol (100\% das cepas testadas) e à amoxicilina (94\% das cepas testadas), enquanto $72 \%$ e $65 \%$ das cepas foram susceptiveis à tetraciclina e ciprofloxacina, respectivamente. O metronidazol e a amoxicilina parecem ser os antimicrobianos indicados para o tratamento de infecções periodontais nas quais $B$. forsythus seja o patógeno predominante.
\end{abstract}

UNITERMOS: Bacteróides; Periodontite; Antibióticos.

\section{INTRODUÇÃO}

Entre as espécies associadas à doença periodontal, Bacteroides forsythus é considerado um patógeno de extrema importância. Tem sido associado à periodontite do adulto, periodontite de progressão rápida e a casos de doença periodontal considerados refratários ${ }^{4,8,9,10}$.

A presença de Bacteroides forsythus na microbiota subgengival é considerada um fator de risco para doença periodontal, aumentando o risco de perda de inserção em 2,5 vezes ${ }^{6}$. Além disso, esta bactéria foi encontrada em maior número em sítios com doença periodontal avançada do que em sítios sadios $^{8}$.

Outro aspecto relevante foi observado por DZINK et al. ${ }^{3}$ (1988), quanto à capacidade de invasão dos tecidos periodontais por este microrganismo. Os autores detectaram $B$. forsythus no tecido conjuntivo adjacente a bolsas periodontais de pacientes portadores de periodontite. DIBART et al. ${ }^{1}$ (1994) também demonstraram que esta espécie bacteriana foi a mais freqüentemente detectada, entre outras periodontopatogênicas, dentro ou sobre células epiteliais da bolsa periodontal. Já em pacientes com periodonto saudável, a detecção de
B. forsythus em células epiteliais foi ocasional. Além destes mecanismos de virulência, B. forsythus produz as enzimas tripsina e sialidase que podem ser importantes na patogênese da doença periodontal ${ }^{13}$.

Devido às características de crescimento lento e dificil deste microrganismo e à necessidade de condições atmosféricas extremamente controladas para o seu cultivo, poucos são os laboratórios que conseguem cultivá-lo e isolá-lo e, portanto, observar mais adequadamente sua associação à doença periodontal, assim como sua susceptibilidade a antimicrobianos.

WISS $^{18}$ (1989) indica o uso do ácido N-acetilmurâmico exógeno como substância suplementar aos meios de cultura para uma melhor proliferação de $B$. forsythus em anaerobiose. O autor relata que esta espécie parece requerer algum fator desconhecido do sangue ou soro para o seu crescimento.

Outras metodologias empregadas para a identificação de $B$. forsythus, como testes imunodiagnósticos ${ }^{4,5,8,9}$, sondas de DNA e RNA e Reação de Polimerase em Cadeia $(\mathrm{PCR})^{2,11}$ têm demonstrado vantagens sobre a cultura deste microrganismo, mas tais testes ainda não são capazes de fornecer

\footnotetext{
* Professor Assistente Doutor; ** Estagiário Didático - Disciplina de Periodontia da Faculdade de Odontologia da USP. *** Aluna de Pós-Graduação em Epidemiologia da Universidade de Michigan, Ann Arbor.
} 
LOTUFO, R. F. M.; PANNUTI, C. M.; SARAIVA, M. da C. Bacteroides forsythus: sensibilidade a antimicrobianos em amostras de pacientes portadores de periodontite. Pesqui Odontol Bras, v. 15, n. 1, p. 47-50, jan./mar. 2001.

a sensibilidade do microrganismo frente aos antimicrobianos disponiveis.

A identificação de $B$. forsythus e a determinação de seu perfil de susceptibilidade a antimicrobianos parecem ser fundamentais no tratamento das doenças periodontais associadas a este microrganismo. Este trabalho teve como objetivo determinar a sensibilidade de cepas de B. forsythus a quatro antimicrobianos usados no tratamento da doença periodontal.

\section{MATERIAIS E MÉTODOS}

\section{Pacientes e amostras da microbiota subgengival}

As amostras subgengivais para o estudo foram obtidas de bolsas periodontais de 105 pacientes entre 15 e 86 anos de idade, portadores de periodontite e com identificação presuntiva positiva para $B$. forsythus por meio de cultura em anaerobiose. Todas as bolsas periodontais apresentaram no mínimo $5 \mathrm{~mm}$ de profundidade e sangramento à sondagem. As amostras foram obtidas por dentistas e enviadas ao Laboratório de Testes em Microbiologia Oral da Faculdade de Odontologia da Universidade do Sul da Califórnia.

Para a obtenção das amostras subgengivais, foram removidos os depósitos supragengivais com curetas periodontais ou bolinhas de algodão. Pontas de papel absorvente foram inseridas nas três bolsas periodontais mais profundas de cada paciente, até que se encontrasse resistência. As pontas foram mantidas no local por 10 segundos e em seguida colocadas em tubos contendo pérolas de vidro e $2 \mathrm{ml}$ de meio de transporte VMGA III ${ }^{12}$, preparado e armazenado em anaerobiose.

\section{Cultivo e identificação de $B$. forsythus}

As amostras em VMGA III foram aquecidas a $35^{\circ} \mathrm{C}$, homogeneizadas mecanicamente (Vortex) durante 1 minuto e alíquotas de $0,1 \mathrm{ml}$, em diluições de 1:1.000, 1:10.000 e 1:100.000 em VMG I, foram semeadas em ágar Brucella sangue a 4,3\% suplementado com $5 \%$ de sangue desfibrinado de carneiro, $0,2 \%$ de hemácias hemolisadas de carneiro, $0,0005 \%$ de hemina e 0,00005\% de menadiona.

Após a incubação a $35^{\circ} \mathrm{C}$, por 5-7 dias, em câmara de anaerobiose* contendo $85 \%$ de nitrogênio, $10 \%$ de hidrogênio e $5 \%$ de gás carbônico, os totais cultiváveis e a contagem de $B$. forsythus foram determinados. Colônias de $B$. forsythus foram identificadas com base nas seguintes características: colônias brancas ou acinzentadas com pontilhados no interior, não fluorescentes à luz ultravioleta, teste de CAAM ( $\mathrm{N}-\alpha$-carbobenzóxi-L-arginina-4-hidrocloreto de metilcumarim) positivo ${ }^{14}$ e bastonetes fusiformes gram-negativos na coloração pelo método de Gram.

Após a identificação e isolamento de $B$. forsythus, foram obtidas culturas puras deste microrganismo. Amostras provenientes das culturas puras foram semeadas em ágar Brucella** suplementado com ácido $\mathrm{N}$-acetilmurâmico ${ }^{18}$ e acrescido de $1 \mu \mathrm{g} / \mathrm{ml}$ de cloridrato de tetraciclina, $1 \mu \mathrm{g} / \mathrm{ml}$ de metronidazol, $1 \mu \mathrm{g} / \mathrm{ml}$ de amoxicilina ou $0,5 \mu \mathrm{g} / \mathrm{ml}$ de ciprofloxacina, conforme metodologia descrita por FLYNN; SLOTS ${ }^{7}$ (1993). As amostras foram incubadas em atmosfera de anaerobiose por 7 a 10 dias.

\section{Análise estatística}

Para verificar se havia diferença entre o número de cepas sensiveis aos quatro antimicrobianos testados, foram realizados testes de comparação de proporções com teste qui-quadrado. Quando o valor esperado foi menor que 5 , usou-se o método de Fisher. Uma vez que foram testadas seis hipóteses, o nivel de significância dos testes foi 0,008 (correção de Bonferroni).

\section{RESULTADOS}

A distribuição das cepas de acordo com a sensibilidade aos antimicrobianos é mostrada na Tabela 1.

Foi observado que $100 \%$ das amostras isoladas foram sensiveis ao metronidazol (MET). Aproximadamente $94 \%$ e $75 \%$ das cepas foram susceptiveis à amoxicilina (AMO) e à tetraciclina (TET), respectivamente. Apenas $62 \%$ mostraram-se sensiveis à ciprofloxacina (CIP).

Não houve diferença estatisticamente significativa entre o número de cepas sensiveis a MET e AMO $(p=0,013)$. O número de cepas sensiveis a MET foi significativamente maior que o número de cepas suscetiveis à TET $(\mathrm{p}=0,001)$ e CIP $(p<0,001)$. Amoxicilina foi significativamente mais eficiente que TET $(p=0,001)$ e CIP $(p=0,001)$. Não houve diferença entre TET e CIP $(p=0,052)$.

\section{DISCUSSÃO}

Neste estudo, foi realizado teste de sensibilidade antimicrobiana in vitro, pela técnica de diluição

\footnotetext{
* Coy Laboratory Products.

** BBL Microbiology System.
} 
LOTUFO, R. F. M.; PANNUTI, C. M.; SARAIVA, M. da C. Bacteroides forsythus: sensibilidade a antimicrobianos em amostras de pacientes portadores de periodontite. Pesqui Odontol Bras, v. 15, n. 1, p. 47-50, jan./mar. 2001.

TABELA 1 - Distribuição das cepas de Bacteroides forsythus de acordo com a sensibilidade a antimicrobianos.

\begin{tabular}{l|rr}
\hline \multicolumn{1}{c|}{ Perfil de sensibilidade antimicrobiana } & $\begin{array}{c}\text { Número e } \\
\% \text { de cepas }\end{array}$ \\
\hline Sensível a MET, AMO, TET e CIP & $49 \quad(46,6)$ \\
\hline Sensível a MET, AMO e TET; resistente a CIP & $26 \quad(24,7)$ \\
\hline Sensível a MET, AMO e CIP; resistente a TET & 15 & $(14,3)$ \\
\hline Sensível a MET e AMO; resistente a TET e CIP & 9 & $(8,6)$ \\
\hline Sensível a MET, TET e CIP; resistente a AMO & 2 & $(1,9)$ \\
\hline Sensível a MET e TET; resistente a AMO e CIP & 2 & $(1,9)$ \\
\hline Sensível a MET; resistente a TET, AMO e CIP & 2 & $(1,9)$ \\
\hline Total & $105(100)$ \\
\hline \hline
\end{tabular}

Obs.: $\mathrm{MET}=1 \mu \mathrm{g}$ de metronidazol; $\mathrm{AMO}=1 \mu \mathrm{g}$ de amoxicilina; $\mathrm{TET}=1 \mu \mathrm{g}$ de tetraciclina; $\mathrm{CIP}=0,5 \mu \mathrm{g}$ de ciprofloxacina.

em ágar, para 105 cepas de $B$. forsythus de pacientes portadores de periodontite. De acordo com os resultados, o metronidazol foi o antimicrobiano de maior ação sobre o microrganismo estudado. Nenhuma das cepas mostrou-se resistente ao metronidazol. A amoxicilina também mostrou bons resultados, sendo aproximadamente $94 \%$ das cepas sensiveis a esta droga.

A necessidade da realização de testes de susceptibilidade antimicrobiana in vitro está baseada nos seguintes fatos: existe uma correlação entre os resultados da susceptibilidade in vitro e o resultado clínico; a susceptibilidade a alguns agentes antimicrobianos varia consideravelmente entre espécies periodontopatogênicas; a resistência antimicrobiana continua a aumentar; podem existir variações regionais no padrão de sensibilidade; o dentista pode querer saber os resultados por motivos médico-legais ${ }^{15}$.

Existem várias metodologias disponíveis para avaliar o perfil de susceptibilidade antimicrobiana in vitro. Os métodos mais utilizados têm sido: teste de difusão de disco, técnica de diluição em ágar, teste de diluição em caldo de cultura e o "E-test".

Apesar de ser de difícil execução, o teste de diluição em ágar parece ser o mais adequado para o crescimento de bactérias anaeróbias de dificil cultivo pelos métodos microbiológicos tradicionais, como é o caso de $B$. forsythus ${ }^{15}$.

Devido à sua capacidade de invadir o tecido periodontal ${ }^{1}$, Bacteroides forsythus pode resistir ao tratamento periodontal convencional. Nestes casos, pode tornar-se necessário o uso de antimicrobianos específicos para eliminar este patógeno.
A prescrição de antibióticos deve obedecer a critérios baseados no conhecimento do perfil de susceptibilidade a antimicrobianos das espécies bacterianas envolvidas na doença, e nas propriedades farmacodinâmicas da droga a ser indicada. A realização de antibiograma, apesar de suas reconhecidas limitações, é uma norma que deveria ser seguida nos casos de indicação precisa de antibioticoterapia complementar ao tratamento periodontal convencional.

Poucos relatos na literatura sobre a susceptibilidade a antimicrobianos do $B$. forsythus foram encontrados. WINKEL et al. ${ }^{16}$ (1997) verificaram o efeito do desbridamento mecânico associado ao uso sistêmico de metronidazol $(500 \mathrm{mg}$, 3 vezes ao dia) em 27 pacientes com periodontite refratária. Os pacientes albergavam placa subgengival positiva para $B$. forsythus e negativa para Actinobacillus actinomycetemcomitans. Após o tratamento mecânico e antimicrobiano, $B$. forsythus foi eliminado em 17 dos 27 indivíduos, havendo melhora correspondente nos parâmetros clínicos.

WINKEL et al. ${ }^{17}$ (1998) avaliaram os efeitos clinicos e microbiológicos da terapia mecânica associada a antibioticoterapia sistêmica em 22 pacientes. Após administração da associação de metronidazol (250 mg, 3 vezes ao dia) com amoxicilina (375 mg, 3 vezes ao dia), os autores observaram a eliminação de $B$. forsythus em 13 dos 14 individuos que apresentavam o microrganismo no início do estudo.

Pelo exposto, nossos resultados são comparáveis aos relatos encontrados na literatura. $\mathrm{O}$ metronidazol e a amoxicilina parecem ser drogas de grande eficiência no tratamento de infecções periodontais nas quais o Bacteroides forsythus seja o patógeno preponderante. Embora existam dificuldades no seu cultivo, consideramos importante a realização de um diagnóstico microbiológico para determinar a presença ou ausência desta bactéria, assim como sua sensibilidade a antimicrobianos.

\section{CONCLUSÕES}

Os resultados obtidos permitem concluir que:

1 . todas as amostras de $B$. forsythus isoladas foram sensiveis ao metronidazol;

2. 94\% das amostras foram sensiveis à amoxicilina. Não houve diferença estatisticamente significativa entre o número de cepas sensiveis a metronidazol e amoxicilina;

3. metronidazol e amoxicilina foram significativamente mais eficientes que tetraciclina e ciprofloxacina. 
LOTUFO, R. F. M.; PANNUTI, C. M.; SARAIVA, M. da C. Bacteroides forsythus: sensibilidade a antimicrobianos em amostras de pacientes portadores de periodontite. Pesqui Odontol Bras, v. 15, n. 1, p. 47-50, jan./mar. 2001.

LOTUFO, R. F. M.; PANNUTI, C. M.; SARAIVA, M. da C. Bacteroides forsythus: sensitivity to antimicrobial agents in samples from patients with periodontitis. Pesqui Odontol Bras, v. 15, n. 1, p. 47-50, jan./mar. 2001.

An in vitro antimicrobial sensitivity test (technique of agar dilution) was carried out for 105 clinical isolates of $B$. forsythus from patients with periodontitis. Metronidazole and amoxicillin were the most efficient drugs and, thus, are indicated for the treatment of periodontal infections in which this microorganism is the most prevalent pathogen.

UNITERMS: Bacteroides; Periodontitis; Antibiotics.

\section{REFERÊNCIAS BIBLIOGRÁFICAS}

1. DIBART, S.; SKOBE, Z.; SNAPP, K. et al. Detection of subgingival species on or in epithelial cells. J Dent Res, v. 78, p. 161, 1994 [Abstract n. 475].

2. DIX, K.; WATANABE, S. M.; McARDLE, S. et al. Speciesspecific oligodeoxynucleotide probes for the identification of periodontal bacteria. J Clin Microbiol, v. 28, n. 2, p. 319-323, Feb. 1990.

3. DZINK, J. L.; SOCRANSKY, S. S.; HAFAJEE, A. The predominant cultivable microbiota of active and inactive lesions of destructive periodontal diseases. J Clin Periodontol, v. 15, n. 5, p. 316-323, May 1988.

4. GERSDORF, H.; MEISSNER, A.; PELZ, K. et al. Identification of Bacteroides forsythus in subgingival plaque from individuals with advanced periodontitis. J Clin Microbiol, v. 31, n. 4, p. 941-946, Apr. 1993.

5. GMUR, R. Applicability of monoclonal antibodies to quantitatively monitor subgingival plaque for specific bacteria. Oral Microbiol Immunol, v. 3, n. 4, p. 187-191, Dec. 1988.

6. GROSSI, S. G.; ZAMBON, J. J.; HO, A. W. et al. Assessment of risk for periodontal diseases. I - risk indicators for attachment loss. J Periodontol, v. 65, n. 3, p. 260-267, Mar. 1994.

7. FLYNN, M. J.; SLOTS, J. Beta-hemolytic streptococci in advanced periodontitis. Oral Microbiol Immunol, v. 8, n. 4, p. 295-297, Apr. 1993.

8. HAFFAJEE, A. D.; SOCRANSKY, S. S.; DZINK, J. L. et al. Clinical, microbiological and immunological features of subjects with refractory periodontal diseases. J Clin Periodontol, v. 15, n. 6, p. 390-398, July 1988.

9. LAI, C. H.; LISTGARTEN, M. A.; SHIRAKAWA, M.; SLOTS, J. Bacteroides forsythus in adult gingivitis and periodontitis. Oral Microbiol Immunol, v. 2, n. 4, p. 152-157, Dec. 1987.
10. LISTGARTEN, M. A.; LAI, C. H.; YOUNG, V. Microbial compositions and pattern of antibiotic resistance in subgingival microbial samples from patients with refractory periodontitis. J Periodontol, v. 64, n. 3, p. 155-161, Mar. 1993.

11. LOTUFO, R. F. M.; FLYNN, J.; CHEN, C.; SLOTS, J. Molecular detection of Bacteroides forsythus in human periodontitis. Oral Microbiol Immunol, v. 9, n. 3, p. 154-160, June 1994.

12. MÖLLER, A. J. R. Microbiological examination of root canals and periapical tissues of human teeth. Odontol Tidskr, v. 74, 380 p., 1966. Supplement.

13. MONCLA, B.; BRAHAM, P.; HILLIER, S. L. Sialidase (neuramidase) activity among gram-negative anaerobic and capnophilic bacteria. J Clin Microbiol, v. 28, n. 3, p. 422-425, Mar. 1990.

14. SLOTS, J. Detection of colonies of Bacteroides gingivalis by a rapid fluorescence assay for trypsin-like enzyme activity. Oral Microbiol Imunnol, v. 2, n. 3, p. 139-141, Sep. 1987.

15. VAN WINKELHOFF, A. J.; RAMS, T. E.; SLOTS, J. Systemic antibiotic therapy in periodontics. Periodontol 2000, v. 10, p. 45-78, Feb. 1996.

16. WINKEL, E. G.; VAN WINKELHOFF, A. J.; TIMMERMAN, M. F. et al. Effects of metronidazole in patients with refractory periodontitis associated with Bacteroides forsythus. J Clin Periodontol, v. 24, n. 8, p. 573-579, Aug. 1997.

17. WINKEL, E. G.; VAN WINKELHOFF, A. J.; VAN DER VELDEN, U. Additional clinical and microbiological effects of amoxicillin and metronidazole after initial periodontal therapy. J Clin Periodontol, v. 25, n. 11, p. 875-864, Nov. 1998.

18. WISS, C. Dependence of proliferation of Bacteroides forsythus on exogenous N-acetylmuramic acid. Infect Imun, v. 57, n. 6, p. 1757-1759, June 1989.

Recebido para publicação em 22/02/00

Enviado para reformulação em 15/08/00

Aceito para publicação em 23/11/00 